\title{
Perceived Importance of Sustainability and Ethics Related to Fish: A Consumer Behavior Perspective
}

\begin{abstract}
Although sustainability and ethics are of increasing public importance, little research has been conducted to reveal its association with fish consumer behavior. Crosssectional data were collected through a postal selfadministered survey (June 2005) from a sample of 381 Flemish women aged 20-50 years. Consumers attach high perceived importance to sustainability and ethics related to fish. However, this perceived importance is neither correlated with fish consumption frequency nor with general attitude toward eating fish. Refusing to eat wild fish is grounded in sustainability and ethical concerns, whereas the decision not to eat farmed fish is associated with a lower expected intrinsic quality rather than shaped by importance attached to sustainability and ethical issues.
\end{abstract}

\section{INTRODUCTION}

Interest in sustainability in general and in sustainable food production and consumption more specifically has increased at all levels of the agriculture and food chain, not in the least at the consumer level (1-6). Sustainable consumption (7-9) comprises a decision-making process that takes the consumer's social responsibility and the needs of future generations into account in addition to individual needs and wants (10). This trend has resulted in the emergence of the ethical consumer, who perceives a direct link between what is consumed and the social issue itself $(2,11)$. In general, the ethical consumer feels responsibility toward society and expresses these feelings by means of his or her purchase behavior (12).

The worldwide consumption of fish and derived fish products has greatly increased during recent decades, mainly owing to the contribution of fish to a healthy human diet, the increasing world population, higher living standards, and the good overall image of fish among consumers $(13,14)$. This increase in demand has led to an expansion of the fishing fleet. Together with a higher fish capture efficiency, this has contributed to overfishing and the risk for depletion of some natural fish stocks (15) as well as an urgent need to adopt more sustainable fisheries management to restore marine biodiversity and safeguard the contribution of fisheries to food security (16, 17). In response to the overfishing of wild fish stocks and the increasing consumer demand for fish, consumers are now offered farmed fish as a valuable alternative (13). Whereas overfishing led to an unsustainable image for the fisheries sector, aquaculture also is associated with some potential negative environmental externalities. These include, for instance, the overfishing of species used for producing fish feed, the modification of coastal ecosystems and habitats, effluents leading to degraded water quality, and impacts on biodiversity from escapees or from the use of wild-caught fry or juveniles $(18,19)$. However, as aquaculture grows worldwide, the concept of sustainable aquaculture is increasingly recognized, and practitioners discover more and more that sustainable aquacul- ture must - apart from maximizing benefits and profits - also minimize negative impacts on the natural and social environment $(19,20)$. With regard to ethical matters, intensive fish farming, taking place in cages, ponds, or tanks, has led to a series of problems that may be classified as husbandry diseases of animal welfare concern (21). Aquaculture production systems are expected to inevitably present challenges regarding acceptable ethical standards (22).

Little is known about how differences in consumer perception toward fish sustainability issues associate with behavior and about the impact of sustainability and ethical concerns on consumer decision-making toward fish consumption $(4,23)$. Although public interest in sustainability increases and consumer attitudes are mainly positive, behavioral patterns are not univocally consistent with interests, preferences, or attitudes. This is referred to as the attitude-behavior gap: attitudes alone are often a poor predictor of behavioral intention or marketplace behavior $(4,24,25)$. Potential explanations are that taste, price, quality, convenience, and brand familiarity are still the most important purchasing decision criteria $(26,27)$, whereas sustainability or ethical attributes are only effectively taken into account by a minority of consumers. In addition, ethical products often have limited availability, are seldom visibly displayed in the shop, and/or are inadequately promoted (13). Few consumers have a high awareness or comprehension of the real sustainability or ethical character of products. The benefits of sustainable products are often poorly communicated to consumers, so that they are unable to make fully informed purchasing decisions in accordance with their preference, budget, and/or conscience. Furthermore, consumers have limited knowledge of food production processes in general and lack insight into the implications of their food purchase decisions on the food supply chain (28). Besides, sustainability is a credence attribute, which means that consumers cannot evaluate it personally through experiencing the good, but must put trust in the source that makes the claim.

The objective of this article is to reveal the importance consumers attach to sustainability issues and ethical matters related with fish in general and to explore its association with fish consumption, attitude toward fish, and several individual characteristics. Furthermore, the aim is to typify consumers who claim to refuse to eat either farmed or wild fish. The expectation is that a higher importance attached to sustainability and ethics related to fish will associate with lower fish consumption frequency. Because of the scarcity of previous studies in this particular field, whether this association holds both for wild and farmed fish is an empirical issue to be investigated from the current dataset.

\section{METHOD}

\section{Study Design and Subjects}

Survey data were collected through questionnaires in Flanders (the Northern Dutch-speaking part of Belgium) during June 2005, after pretesting in May 2005. The population for this 


\begin{tabular}{|lr|}
\hline $\begin{array}{l}\text { Table 1. Socio-demographic characteristics of the sample }(\%, \mathbf{n}= \\
\text { 381). }\end{array}$ & $\%$ \\
\hline & \\
\hline Age & \\
20 to 29 years & 14.2 \\
30 to 39 years & 55.5 \\
20 to 29 years & 30.3 \\
Profession & \\
Self-employed & 10.5 \\
Employee & 64.6 \\
Worker & 5.2 \\
Housewife & 5.0 \\
Others & 14.7 \\
Education & \\
$\quad \leq 18$ years & 28.9 \\
$>18$ years & 71.1 \\
Kids in the family & \\
Yes & 85.6 \\
No & 14.4 \\
Family size & 14.5 \\
1 or 2 people & 63.5 \\
3 or 4 people & 22.0 \\
5 or more people & \\
\hline
\end{tabular}

study was defined as women aged between 20 and 50 years (29). This target group was selected based on our interest in recruiting respondents having the main responsibility for food purchase in the household. This population is also very relevant to investigate because it consists mainly of women at childbearing age and also, in most cases, households with young children, who constitute a major target audience for public health recommendations with respect to fish consumption. The questionnaires were distributed to mothers through randomly selected primary and nursery schools. All questionnaires were self-administered at the home of the respondent and returned by post to the research unit. A total of 1430 questionnaires were distributed, of which 431 were returned, yielding a gross response of $30.1 \%$. After eliminating the blank and incomplete questionnaires and those completed by men, 381 were valid, which corresponds with a valid response rate of $26.6 \%$. The sample includes respondents from a variety of age (within the 20-50-year interval), educational, and professional categories (Table 1). Note that the specific respondent selection and recruiting procedures do not yield a statistically representative sample. Hence, findings mainly apply within the characteristics of the sample, whereas generalization to the overall population remains speculative.

\section{Questionnaire and Scales}

The questionnaire includes six components relevant to food consumer science. The selection of items and scales is partly based on the questionnaire used in the pan-European SEAFOODplus consumer study $(30,31)$.

First, fish consumption frequency during the past month was measured using a ratio scale ranging from "never" to " 15 times or more." Also, fish consumption frequency of six of the most common fish species in Belgium (cod, salmon, tuna, pollack, sole, and trout) was measured on a nine-point scale ranging from "never" to "daily."

Second, consumer attitude toward eating fish was assessed using two multi-item questions. The first probed about general consumer attitude toward eating fish using six bipolar items on a seven-point semantic differential scale (e.g., bad-good, negative-positive). The second attitude question probed for attribute beliefs, again using six bipolar items and a seven-point semantic differential scale (e.g. unhealthy-healthy, unsafe-safe).

Third, five questions regarding perceived importance of sustainability (three items) and ethical issues (two items) with respect to fish production and consumption were incorporated.
Concerning sustainability, the perceived importance of "avoiding depletion of natural fish resources," "applying environmentally-friendly catch and production methods," and "adopting non-polluting production processes," was measured. With regard to ethics, the perceived importance of "reducing animal (fish) suffering" and "respecting the rights and welfare of the fish during catch and production" was sought. This selection of items was informed by literature review $(19,22)$ and focus group discussions with consumers (32) that revealed these items and their respective formulations as the most prominent among consumers. All five items were measured on a seven-point interval scale.

Fourth, subjective knowledge was probed, again using a seven-point Likert scale and including three statements: "Compared to an average person, I know a lot about fish," "My friends consider me as an expert in the domain of fish," "I know a lot about how to evaluate the quality of fish."

Fifth, some questions about interest in information were included, all on seven-point interval scales. First, the expected benefit in terms of improved fish welfare and conservation of natural fish resources from providing more information was sought. Also, consumer interest in receiving information about the capture area and the origin of fish (farmed or wild) was measured.

Sixth, perceived consumer effectiveness was assessed using a single item: "Through my personal choice of fish, I can contribute to the saving of natural fish stocks from depletion."

Finally, the respondents were asked whether they would not buy farmed or wild fish when being clearly informed that this fish had a farmed or wild origin, respectively. This measure enabled us to identify market segments who (claim to) refuse to eat either farmed or wild fish.

\section{Statistical Analyses}

Data were analyzed using SPSS 12.0. Means and standard deviations are presented in table format. Construct reliability was tested by Cronbach's alpha. Bivariate analyses through correlation and comparison of mean scores, i.e., independentsamples t-tests and analysis of variance (ANOVA) F-tests with Bonferonni and Dunnett's T3 posthoc comparison of mean scores, were used to assess correlation and association between interval scaled variables on the one hand and categorical variables on the other hand. Cross-tabulation with chi-square statistics were used to control for equal distributions between categorical variables.

\section{RESULTS}

\section{Construct Reliability}

The six bipolar items measuring general attitude toward fish yielded a highly satisfactory Cronbach's alpha of 0.95 . Also, the five items dealing with sustainability and ethical issues (alpha $=$ $0.93)$, the three subjective knowledge items $($ alpha $=0.82)$ and the two items about expected benefit from additional information provision $($ alpha $=0.80)$ yielded satisfactory reliability consistency. Hence, items were merged, and a composite construct score was calculated for "general attitude," "perceived importance of sustainability and ethics," "subjective knowledge," and "expected benefit from information."

\section{Description of Mean Values}

Participants consumed fish, on average, 4.6 times per month, with $61.7 \%$ eating fish at least once a week (Table 2); $1.6 \%$ did not consume fish in the past month. Of the fish types included, salmon, cod, and tuna were most frequently consumed, whereas 


\begin{tabular}{|c|c|c|}
\hline Item & Mean & SD \\
\hline \multicolumn{3}{|l|}{ Behavior (consumption frequency) } \\
\hline Total fish (per month) & 4.55 & 2.57 \\
\hline Tuna (per week) & 0.44 & 0.80 \\
\hline Salmon (per week) & 0.43 & 0.41 \\
\hline Cod (per week) & 0.40 & 0.40 \\
\hline Pollack (per week) & 0.19 & 0.41 \\
\hline Sole (per week) & 0.17 & 0.19 \\
\hline Trout (per week) & 0.09 & 0.28 \\
\hline \multicolumn{3}{|l|}{ Attitude (seven-point scale) } \\
\hline General attitude (construct) & 5.62 & 1.11 \\
\hline \multicolumn{3}{|l|}{ Eating fish is: } \\
\hline healthy & 6.43 & 0.83 \\
\hline nutritious & 6.29 & 0.95 \\
\hline favorable & 5.65 & 1.20 \\
\hline ethical & 5.32 & 1.27 \\
\hline safe & 5.29 & 1.17 \\
\hline cheap & 3.13 & 1.43 \\
\hline \multicolumn{3}{|l|}{$\begin{array}{l}\text { Importance attached to sustainability and } \\
\text { ethics (seven-point scale) }\end{array}$} \\
\hline Adopting a nonpolluting production process & 5.86 & 1.45 \\
\hline $\begin{array}{l}\text { Applying environmental-friendly catch and } \\
\text { production }\end{array}$ & 5.68 & 1.51 \\
\hline Avoiding depletion of natural fish stocks & 5.60 & 1.54 \\
\hline Reducing animal (fish) suffering & 5.16 & 1.69 \\
\hline Respecting the rights and welfare of fish & 5.26 & 1.65 \\
\hline Construct* ${ }^{*}$ & 5.51 & 1.39 \\
\hline \multicolumn{3}{|l|}{ Subjective knowledge (seven point scale) } \\
\hline Construct* & 3.00 & 1.29 \\
\hline \multicolumn{3}{|l|}{$\begin{array}{l}\text { Perceived consumer effectiveness (seven } \\
\text { point scale) }\end{array}$} \\
\hline $\begin{array}{l}\text { Through my personal choice of fish, I can } \\
\text { contribute ... }\end{array}$ & 4.11 & 1.47 \\
\hline \multicolumn{3}{|l|}{ Information (seven point scale) } \\
\hline Interest in fish origin & 3.49 & 1.67 \\
\hline Interest in capture area & 2.83 & 1.93 \\
\hline $\begin{array}{l}\text { Expected benefit from more information } \\
\text { (construct) }\end{array}$ & 4.58 & 1.34 \\
\hline
\end{tabular}

sole, Pollack, and trout were less frequently consumed. This pattern of salmon, cod, and tuna as the most common fish species followed at quite a distance by other species matches well with household panel data and earlier findings from fish consumer studies in Belgium (30, 33, 34).

The general attitude toward eating fish was very positive. Respondents were most strongly convinced that eating fish is healthy and nutritious. People were less pronounced but still positive toward eating fish as being ethical and safe, and they agreed upon fish being rather expensive. With regard to sustainability and ethics, a high perceived importance was reported $(\mu=5.51)$, with the sustainability issues receiving higher scores than the ethical issues. In general, these attitudes corroborate findings from previous fish consumer studies, as will be discussed later in the Discussion.

Perceived consumer effectiveness was scored neutral $(\mu=$ $4.11)$, whereas a rather low subjective knowledge $(\mu=3.00)$ was reported. There was a small but positive expected benefit from more information on sustainability and ethics $(\mu=4.83)$, whereas interest in both capture area and origin (farmed versus wild) was quite low (2.83 and 3.49, respectively).

\section{Importance Attached to Sustainability and Ethical Issues}

Bivariate correlations were used to link importance attached to sustainability and ethical issues with respondent's age, fish consumption frequency, general attitude, perceived consumer effectiveness, subjective knowledge, interest in capture area and origin, and expected benefit from more information (Table 3).

With respect to sociodemographics, only age emerged as a determinant of importance attached to sustainability and ethics.

\section{Table 3. Correlations with perceived importance of sustainability} and ethical issues.

\begin{tabular}{|c|c|c|}
\hline & \multicolumn{2}{|c|}{$\begin{array}{l}\text { Perceived importance of } \\
\text { sustainability and ethical } \\
\text { issues associated with } \\
\text { fish consumption }\end{array}$} \\
\hline & Pearson $r$ & $\mathbf{p}$ \\
\hline Age & 0.14 & 0.010 \\
\hline Behavior (fish consumption frequency) & 0.10 & 0.064 \\
\hline General attitude & 0.08 & 0.151 \\
\hline Perceived consumer effectiveness & 0.27 & 0.000 \\
\hline Subjective knowledge & 0.12 & 0.025 \\
\hline Interest in capture area & 0.25 & 0.000 \\
\hline Interest in fish origin (farmed/wild) & 0.22 & 0.000 \\
\hline Expected benefit from more information & 0.43 & 0.000 \\
\hline
\end{tabular}

The positive and significant correlation indicates a higher perceived importance of sustainability and ethical issues among older consumers; note though that these findings are to be interpreted within the specifics of the sample (age range 20-50 years). A positive but nonsignificant correlation was found between importance attached to sustainability and ethical issues and both fish consumption frequency and general attitude toward eating fish. A positive and highly significant correlation was found with perceived consumer effectiveness, indicating that those who consider ethical and sustainability issues to be more important also believe they can contribute through their own personal choice and behavior. Also, subjective knowledge correlated positively, although only moderately, with the perceived importance of sustainability and ethical issues. Finally, an interest in capture area, origin, and expected benefit from information were positively correlated with perceived importance of ethical and sustainability issues. These findings indicate that consumers associate capture area and fish origin, at least to some extent, with different degrees of sustainability and ethics. The strongly positive correlation with the expected benefit from more information indicates that the more a consumer perceives sustainability and ethical issues as important, the more she feels that additional information provision can contribute to better fish welfare and sustainability in fisheries and aquaculture.

\section{Refusing to Eat Farmed or Wild Fish}

Respectively, 10.2\% $(\mathrm{n}=39)$ and $11.7 \%(\mathrm{n}=45)$ of the respondents declared a refusal to eat either farmed or wild fish when clearly informed about the fish's origin. These subsamples are small but substantial enough to be characterized. Crosstabulation indicates that these groups are not composed of the same individuals (Table 4).

Overall fish consumption frequency and consumption frequency of different fish types are of particular interest with regard to behavior. Salmon and trout, for instance, are expected to be less accepted by respondents indicating a refusal to eat farmed fish because both species are mainly farmed. The other fish species, such as cod, tuna, Pollack, and sole, that are available on the Belgian market are still mainly or exclusively wild captured through fisheries.

The highest total fish consumption frequency was reported by the subsample claiming to refuse eating farmed fish. Despite nearly one unit of observed difference in terms of fish consumption frequency per month as compared with consumers who accept farmed fish, this difference is not statistically significant. With respect to wild fish, an opposite tendency is seen, with those claiming to refuse eating wild fish reporting a lower (and overall lowest) total fish consumption frequency. The latter difference is marginally significant $(0.05<\mathrm{p}<0.10)$. 
Table 4. Characterizing consumers who refuse to eat farmed or wild fish $(n=381)$.

\begin{tabular}{|c|c|c|c|c|c|c|}
\hline & \multicolumn{3}{|c|}{ Refuse to eat farmed fish } & \multicolumn{3}{|c|}{ Refuse to eat wild fish } \\
\hline & $\begin{array}{c}\text { Yes } \\
(n=39)\end{array}$ & $\begin{array}{c}\text { No } \\
(n=342)\end{array}$ & $\mathbf{p}$ & $\begin{array}{c}\text { Yes } \\
(n=45)\end{array}$ & $\begin{array}{c}\text { No } \\
(n=336)\end{array}$ & $\mathbf{p}$ \\
\hline \multicolumn{7}{|l|}{ Behavior } \\
\hline Overall consumption frequency* & 5.43 & 4.48 & 0.126 & 3.88 & 4.67 & 0.063 \\
\hline Tuna $^{\dagger}$ & 0.81 & 0.40 & 0.172 & 0.61 & 0.42 & 0.173 \\
\hline Salmon ${ }^{\dagger}$ & 0.51 & 0.40 & 0.154 & 0.46 & 0.40 & 0.604 \\
\hline $\mathrm{Cod}^{\dagger}$ & 0.44 & 0.39 & 0.480 & 0.53 & 0.37 & 0.127 \\
\hline Pollack ${ }^{\dagger}$ & 0.24 & 0.19 & 0.537 & 0.18 & 0.19 & 0.856 \\
\hline Sole $^{\dagger}$ & 0.18 & 0.17 & 0.631 & 0.15 & 0.17 & 0.438 \\
\hline Trout $^{\dagger}$ & 0.08 & 0.08 & 0.889 & 0.05 & 0.09 & 0.282 \\
\hline \multicolumn{7}{|l|}{ Attitude } \\
\hline General attitude & 5.73 & 5.61 & 0.554 & 5.42 & 5.66 & 0.338 \\
\hline Healthy $y^{\ddagger}$ & 6.63 & 6.40 & 0.126 & 6.28 & 6.44 & 0.249 \\
\hline Nutritious & 6.60 & 6.25 & 0.040 & 6.28 & 6.29 & 0.940 \\
\hline Favorable $^{\ddagger}$ & 5.71 & 5.65 & 0.753 & 5.80 & 5.64 & 0.426 \\
\hline Ethical $^{\ddagger}$ & 5.20 & 5.34 & 0.530 & 5.10 & 5.36 & 0.280 \\
\hline Safe $^{\ddagger}$ & 5.31 & 5.32 & 0.842 & 5.40 & 5.31 & 0.229 \\
\hline Cheap $\ddagger$ & 2.83 & 3.21 & 0.413 & 3.23 & 3.17 & 0.786 \\
\hline \multicolumn{7}{|l|}{ Subjective knowledge } \\
\hline Construct ${ }^{\ddagger}$ & 3.47 & 2.94 & 0.022 & 2.85 & 3.01 & 0.491 \\
\hline \multicolumn{7}{|l|}{ Sustainability and ethics } \\
\hline Construct ${ }^{f}$ & 5.47 & 5.51 & 0.900 & 6.01 & 5.44 & 0.016 \\
\hline \multicolumn{7}{|l|}{ Perceived consumer effectiveness } \\
\hline Item & 3.64 & 4.16 & 0.149 & 4.64 & 4.05 & 0.046 \\
\hline \multicolumn{7}{|l|}{ Information } \\
\hline Interest in origin (farmed/wild) & 4.51 & 3.39 & 0.001 & 4.22 & 3.39 & 0.007 \\
\hline Expected benefit from more info & 4.73 & 4.58 & 0.513 & 5.31 & 4.50 & 0.000 \\
\hline
\end{tabular}

Significant differences in consumption frequency at species level were not seen between respondents who do or do not refuse to eat farmed fish nor between respondent who do or do not abstain from eating wild fish.

Respondents who refuse to eat farmed fish reported a higher mean score for the belief related to the "nutritional value" of fish as compared to those who accept eating farmed fish. A similar tendency was seen with respect to "health" perception, although not statistically significant. Furthermore, consumers refusing to eat farmed fish reported a significantly higher subjective knowledge about fish as compared to those accepting farmed fish. Accepting versus rejecting wild fish consumption did not associate with general attitude, fish attribute perceptions, and subjective knowledge.

Consumers' rejection or acceptance of farmed fish did not differ with their perceived importance attached to sustainability and ethical issues. In contrast, consumers who refuse eating wild fish reported a significantly higher perceived importance of sustainability and ethical issues as compared to those who accept wild fish. Furthermore, consumers refusing wild fish also reported a significantly higher perceived consumer effectiveness and a higher expected benefit from more information.

Finally, and logically, both subsamples who reject fish from a specific origin reported a significantly higher interest in being informed about the origin (farmed or wild) of the fish consumed. Apart from a tendency of lower education in the subsample refusing wild fish, no sociodemographic characterization, e.g., in terms of age or gender, of consumers rejecting either fish origin emerged.

\section{DISCUSSION}

\section{General Picture of Behavioral and Attitudinal Characteristics}

The reported fish consumption frequency of the sample was 4.6 times a month, which is somewhat higher compared to previous studies in Flanders $(33,34)$. This is probably due to the all female composition of the sample. Fish consumption frequency tends to be higher among women (35), most likely owing to women's higher health consciousness as compared to men (36, 37). Response bias, with a higher participation of more involved and heavier fish consumers, may provide another potential explanation for the high fish consumption frequency in the sample. Regarding attitude, previous empirical findings were confirmed with a very positive image of fish consumption among consumers in general $(14,35,38-41)$. More specifically, health and nutritional value emerged as the strongest motives for consuming fish $(35,42,43)$, whereas price was indicated as a barrier. Price also appeared in other studies as a barrier for fish consumption, together with bones, smell, limited availability and choice, and variation in quality $(34,35,38-41,44)$.

\section{Characteristics of Fish Consumers Interested in Sustainability and Ethics}

In general, sustainability and ethics with respect to fish were indicated by consumers as being quite important, which supports previous findings about consumer interest in sustainability in general and which corresponds with a high importance attached to process attributes and postmaterialistic values (1-4). This perceived and claimed importance, however, was neither translated into a significant correlation with total fish consumption frequency nor with general attitude toward eating fish. Hence, sustainability and ethical considerations do not shape attitude and fish consumption behavior to a large extent. A potential explanation is limited consumer awareness of fish origin and related sustainability and ethical issues or ignorance of these issues when forming quality expectations and making purchasing decisions. Nonetheless, these matters entail clear opportunities for food chains. Stakeholders can count on a substantial consumer interest, so the major challenge is to find a way to translate this interest into action in terms of convincing consumers to opt for products with sustainability and ethical benefits. Furthermore, our results characterize the more sustainable fish consumer as an older person (within the considered age range of 20-50 years) who has a higher 
subjective knowledge about fish quality and higher perceived effectiveness. Furthermore, this consumer is more interested in receiving information and expects a higher benefit with respect to sustainability and ethics in fisheries and aquaculture from improved and extended information provision. This characterization fits well with the "ethical consumer" as defined in previous studies $(45,46)$.

\section{Determinants of Either Farmed or Wild Fish Rejection}

The present study reveals some of the reasons why consumers abstain from purchasing or eating either farmed or wild fish when properly informed about fish origin (47). First of all, it must be stressed that the Flemish respondents have little awareness about which fish species are sold as farmed or wild and about how fish is produced in general $(33,34)$. This is important to address regarding the extent to which their intention is translated into actual behavior.

The choice not to eat wild fish seems to have a major part of its basis in sustainability and ethical considerations, given a significantly higher importance attached to these issues by consumers who refuse to eat wild fish. Also, consumers who refuse to eat wild fish (when properly informed about fish origin) have the lowest overall fish consumption frequency and the lowest (though still very positive) attitude toward eating fish. Their interest in fish origin information is most likely driven by their want to avoid wild fish, because of their preference for making a sustainable and ethical choice, which aligns with their higher perceived consumer effectiveness.

The characterization of consumers who refuse to eat farmed fish is very different. These consumers have the highest overall fish consumption frequency and report the most positive attitude towards eating fish, in particular with respect to perceived nutritional value and healthiness of fish. They report a low perceived consumer effectiveness, i.e., they do not feel their own personal choice can make a difference. At the same time, they claim to be quite knowledgeable with respect to fish quality and apparently associate farmed fish with lower intrinsic quality. Their interest in information about fish origin is driven by their preference for wild fish and desired avoidance of farmed fish, which in the end is not shaped by ethical considerations. Sustainability and ethics are either not (or less) associated with farmed fish (in these consumers' perceptions), or they are outweighed by expectations on intrinsic quality attributes, such as nutritional value, healthiness, and probably also taste, and/or ignored when making a fish purchasing decision. This picture is consistent with previous findings indicating that wild fish is perceived as more healthy and tasty, in particular among heavy fish consumers for whom taste and health are major fish consumption motives (48). Furthermore, the higher absolute scores for general attitude, health, and nutritional value by the group refusing to eat farmed fish corroborates previous studies (49-51) where farmed fish was perceived worse than wild fish on these issues, in contrast with scientific evidence reporting the absence of systematic safety and healthiness differences on the basis of fish being farmed versus wild (52). The main cause of this gap between consumer perception and scientific evidence seems to be the lack of consumer knowledge concerning aquaculture, resulting in the use of emotions to judge farmed fish and its "industrial" production process as less positive than the "natural" wild fish $(51,53)$.

\section{Limitations}

This study faces some limitations related to its sampling and questioning. The sample is limited to women aged $20-50$ years from Flanders, Belgium. As a result, this study only reports a behavioral perspective of a rather narrow population or sociodemographic group, with a higher than average fish consumption frequency, and an overrepresentation of families with children and higher education. Future studies focusing on the cross-cultural validity of our findings and applicability to other sociodemographic fish consumer groups are recommended. It is also important to note that the findings from this study did not result from direct questioning, e.g., we did not directly probe about reasons for refusing to eat wild or farmed fish. This approach has the advantage that it avoids socially desirable answering to a large extend, but also brings along the disadvantage of not proving any causality, only association.

\section{CONCLUSION}

Based on a consumer survey performed in June 2005, this article examined consumers' perceived importance of sustainability and ethical issues related to fish and its relationship with fish consumption frequency, attitude toward eating fish, subjective knowledge, sociodemographics, and the eventual refusal to eat either farmed or wild fish. In general, sustainability and ethical issues were indicated as being important. However, for a large majority of the participants, this high interest is not associated with attitude and behavior. The rejection of wild fish seems to be partly based on sustainability and ethical considerations, whereas refusing farmed fish is more because of a lower intrinsic quality expectation rather than being shaped by sustainability and ethical considerations. These findings also point to the need for more communication to consumers regarding sustainability and ethical issues in relation to wild/farmed fish. Not only did consumers seeking to avoid fish of a specific origin express a stronger interest in information in general, but those who refuse wild fish especially expect more direct benefits from being properly informed. Furthermore, because refusing to eat farmed fish seems to be shaped by beliefs that do not match with current scientific evidence, tackling these beliefs with appropriate communication is particularly challenging and entails potential opportunities for the aquaculture industry.

\section{References and Notes}

1. Antil, J.H. 1984. Socially responsible consumers: profile and implications for public policy. J. Macromarketing 4, (2), 18-39.

Shaw, D. and Clarke, I. 1999. Belief formation in ethical consumer groups: an Shaw, D. and Clarke, I. 1999. Belief formation in

3. Follows, S.B. and Jobber, D. 2000. Environmentally responsible purchase behaviour: a test of a consumer model. Eur. J. Marketing 34, 723-746.

4. Vermeir, I. and Verbeke, W. 2006. Sustainable food consumption: exploring the consumer "attitude-behavioral intention" gap. J. Agric. Environ. Ethics 19, 169-194. Shepherd, R., Magnusson, M. and Sjoden, P.O. 2005. Determinants of consumer behavior related to organic foods. Ambio. 34, 352-359.

6. Andersson, R., Algers, B., Bergstrom, L., Lundstrom, K., Nybrant, T. and Sjoden, P.O. 2005. Food 21: a research program looking for measures and tools to increase food chain sustainability. Ambio. 34, 275-282.

7. One of the most authoritative definitions of sustainable consumption is the one proposed by the 1994 Oslo Symposium on Sustainable Consumption, which defines sustainable by the 1994 Oslo Symposium on Sustainable Consumption, which defines sustainable
consumption as "the use of services and related products which respond to basic needs and bring a better quality of life while minimizing the use of natural resources and toxic materials as well as emissions of waste and pollutants over the life cycle of the service or product so as not to jeopardize the needs of future generations" (8). Recommendations for cultivating and promoting more sustainable modes of consumption have been written down recently in the 2005 Oslo Declaration on Sustainable Consumption (9).

8. United Nations Commission on Sustainable Development. 1994. Summary Report: The Symposium on Sustainable Consumption, Oslo, 19-20 Jan 1994. In: General Discussion on Progress in the Implementation of Agenda. UNCSD, New York, pp. 2-5.

9. Tukker, A., Cohen, M.J., de Zoysa, U., Hertwich, E., Hofstetter, P., Inaba, A., Lorek, S. and Stø, E. 2006. The Oslo declaration on sustainable consumption. J. Ind. Ecol. 10, 9-14.

10. Meulenberg, M. 2003. Consumer and citizen, meaning for the market of agricultural products and food products. TSL 18, 43-56 (In Dutch).

1. Tallontire, A., Rentsendorj, E. and Blowfield, M. 2001. Ethical Consumers and Ethical Trade: A Review of Current Literature. Policy Series 12. CAB International, Wallingford, $40 \mathrm{pp}$.

12. De Pelsmacker, P., Driesen, L. and Rayp, G. 2003. Are Fair Trade Labels Good Business? Ethics and Coffee Buying Intentions. Working Paper. Ghent University, Faculty of Economics and Business Administration, Ghent, $27 \mathrm{pp}$.

13. Cahu, C., Salen, P. and De Lorgeril, M. 2004. Farmed and wild fish in the prevention of cardiovascular diseases: assessing possible differences in lipid nutritional values. Nutr. Metab. Cardiovas. 14, 34-41.

14. Bruns $\emptyset$, K. 2003. Consumer research on fish in Europe. In: Quality of Fish from Catch to Consumer: Labelling, Monitoring and Traceability: 2003. Luten, J.B., Oehlenschlaeger, J. Consumer: Labelling, Monitoring and Traceability: 2003. Luten, J.B., Oehlenschlaeger, J.
and Olafsdottir, G. (eds). Wageningen Academic Publishers, Wageningen, pp. 335-344. 15. FAO. 2002. The State of World Fisheries and Aquaculture. FAO information division, Rome, $148 \mathrm{pp}$. 
16. Bruckmeier, K. and Neuman, E. 2005. Local fisheries management at the Swedish coast: biological and social preconditions. Ambio. 34, 91-100.

17. Worm, B., Barbier, E.B., Beaumont, N., Duffy, J.E., Folke, C, Halpern, B.S., Jackson, J.B.C., Lotze, H.K., et al. 2006. Impacts of biodiversity loss on ocean ecosystem services. Science 314, 787-790.

18. Haaland, B. and Esmark, M. 2002. Clean Conscience Consumption of Seafood. A Summary of Eco-labels and Environmental Management Systems for Fisheries and Aquaculture Products. WWF, Oslo, 55 pp.

19 FAO 2006 State of World Aquaculture: 2006. FAO Fisheries Technical Paper 500. Food and Agriculture Organization of the United Nations, Rome, $134 \mathrm{pp}$

20. Frankic, A. and Hershner, C. 2003. Sustainable aquaculture: developing the promise of aquaculture. Aquac. Int. 11, 517-530

21. Poppe, T.T., Barnes, A.C. and Midtlyng, P.J. 2002. Welfare and ethics in fish farming Bull. Eur. Assn. Fish. P 22, 148-151.

22. Bæverfjord, G. 1998. Ethics and Animal Welfare in Intensive Aquaculture Production Farming Marine Fish Beyond the Rear 2000. Technological Solutions for Biological Challenges. ICES CM/1998/L18,3. ICES, Copenhagen, 3 pp.

23. Shaw, D. and Shiu, E. 2003. Ethics in consumer choice: a multivariate modelling approach. Eur. J. Marketing 37, 1485-1498.

24. Kraus, S. 1995. Attitudes and the prediction of behavior-a meta-analysis of the empirical literature. Pers. Soc. Psychol. B 21, 58-75

25. Ajzen, I. 2001. Nature and operation of attitudes. Annu. Rev. Psychol. 52, 27-58.

26. Carrigan, M. and Attalla, A. 2001. The myth of the ethical consumer-do ethics matter in purchase behavior. J. Cons. Marketing 18, 560-577.

27. Weatherell, C. Tregear, A. and Allinson, J. 2003. In search of the concerned consumer: UK public perceptions of food, farming and buying local. J. Rural Stud. 19, 233-244.
Verbeke, W. 2005. Agriculture and the food industry in the information age. Eur. Rev. Verbeke, W. 2005. Agricu
Agric. Econ. 32, 347-368.

29. The combination with an experimental design part of the study dealing with risk-benefi information, which extends beyond the scope of the current paper, necessitated us to narrow down the sociodemographic variance in the sample.

30. Honkanen, P. and Brunsø, K. 2005. On the average European fish consumption is below recommended levels. (http://www.seafoodplus.org/European_fish_consumpt.411. 0.html)

31. Olsen, S.O., Scholderer, J., Bruns $\varnothing$, K. and Verbeke, W. 2007. Exploring the relationship between convenience and fish consumption: a cross-cultural study. Appetite, doi:10. 1016/j.appet.2006.12.002

32. Pieniak, Z., Verbeke, W. Vermeir, I., Brunsø, K. and Olsen, S.O. 2007. Consumer interest in fish information and labeling: exploratory insights. J. Int. Food Agribuss interest in fish inform

33. Verbeke, W. and Vackier, I. 2005. Individual determinants of fish consumption: application of the theory of planned behaviour. Appetite 44, 67-82.

34. Verbeke, W., Sioen, I., Pieniak, Z., Van Camp, J. and De Henauw, S. 2004. Consumer perception versus scientific evidence about health benefits and safety risks from fish consumption. Public Health Nutr. 8, 422-429.

35. Fagerli, R.A. and Wandel, M. 1999. Gender differences in opinions and practices with regard to a "healthy diet". Appetite 32, 171-190.

36. Beardsworth, A., Bryman, A., Keil, T., Goode, J., Haslam, C. and Lancashire, E. 2002. Women, men and food: the significance of gender for nutritional attitudes and choices. Br. Food J. 107, 470-491.

7. Leek, S., Maddock, S. and Foxall, G. 2000. Situational determinants of fish consumption. Br. Food $J$, 102, 18-39.

38. Myrland, O., Trondsen, T., Johnston, R.C. and Lund, E. 2000. Determinants of seafood consumption in Norway: lifestyle, revealed preferences, and barriers to consumption. consumption in Norway: lifestyle,

39. Olsen, S.O. 2001. Consumer involvement in seafood as family meals in Norway: an application of the expectancy-value approach. Appetite 36, 173-186.

40. Trondsen, T., Scholderer, J., Lund, E. and Eggen, A.E. 2003. Perceived barriers to consumption of fish among Norwegian women. Appetite 41, 301-314.

41. Bredahl, L. and Grunert, K.G. 1997. Determinants of the consumption of fish an shellfish in Denmark: an application of the theory of planned behaviour. In: Seafood from Producer to Consumer, Integrated Approach to Quality. Luten, J.B., Børresen, T. and Oehlenschläger, J. (eds). Elsevier, Amsterdam, pp. 21-30.

42. Foxall, G., Leek, S. and Maddock, S. 1998. Cognitive antecedents of consumers willingness to purchase fish rich in polyunsaturated fatty acids (PUFA). Appetite 31, $391-402$.

43. Trondsen, T. 1997. Marketing potential and barriers for fresh packed fish. A survey of buyer perception in UK and French distribution. J. Food Prod. Marketing 4, 79-99.

Trondsen, T. 1997. Value-added fresh fish. Barriers to growth. J. Int. Food Agribus Marketing 8, 55-78.

45. Carrigan, M. and Attalla, A. 2001. The myth of the ethical consumer-do ethics matter in purchase behavior? J. Cons. Marketing 18,560-577.

46. Robinson, R. and Smith, C. 2002. Psychosocial and demographic variables associated with consumer intention to purchase sustainable produced foods as defined by the Midwest Food Alliance. J. Nutr. Educ. Behav. 34, 316-325.
47. This information must be made available to consumers upon fish purchase as specified in Commission Regulation EC 2065/2001

48. Luten, J., Kole, A., Schelvis, R., Veldman, M, Heide, M., Carlehög, M and Akse, L. 2002. Evaluation of wild cod versus wild caught, farmed raised cod from Norway by Dutch consumers. Økonomisk Fiskeriforskning 12, 44-60.

49. Kole, A. 2003. Consumer opinions towards farmed fish, accounting for relevance and individual knowledge. In: Quality of Fish from Catch to Consumer. Labelling, Wageningen Academic Publishers, Wageningen, pp. 393-400

50. Arvanitoyannis, I.S., Krystallis, A., Panagiotiaki, P. and Theodorou, A.J. 2004. A marketing survey on Greek consumers' attitudes towards fish. Aquac. Int. 12, 259-279.

51. Verbeke, W., Sioen, I., Brunsø, K., Van Camp, J. and De Henauw, S. 2007. Consume perception versus scientific evidence of farmed versus wild fish: exploratory insights from Belgium. Aquac Int. (In press).

52. EFSA. 2005. Opinion of the scientific panel on contaminants in the food chain on request from the European Parliament related to the safety assessment of wild and farmed fish. EFSA J. 236, 1-118.

53. Frewer, L.J., Kole, A., Van De Kroon, S.M.A. and De Lauwere, C. 2005. Consumer attitudes towards the development of animal-friendly husbandry systems. J. Agr. Env. Ethics 18, 345-367.

54. Belgian Science Policy (SPSDII-project CP/02/56) and the Institute for the Promotion of Innovation through Science and Technology in Flanders (IWT-Vlaanderen) are acknowledged for financial support.

55. First submitted 14 November 2006. Accepted for publication 18 February 2007

Wim Verbeke is a professor in agro-food marketing, consumer behavior, and food consumer science. His address: Department of Agricultural Economics, Ghent University, Coupure links 653, B-9000 Ghent, Belgium. E-mail: Wim.Verbeke@UGent.be

Filiep Vanhonacker is a doctoral researcher in the area of food consumer science. His address: Department of Agricultural Economics, Ghent University, Coupure links 653, B-9000 Ghent, Belgium.

E-mail: Filiep.Vanhonacker@UGent.be

Isabelle Sioen is a doctoral researcher in the area of nutrition epidemiology. Her address: Department of Public Health, Ghent University, UZ-2 Blok A, De Pintelaan 185, B-9000 Ghent \& Department of Food Safety and Food Quality, Ghent University, Coupure links 653, B-9000 Ghent, Belgium.

E-mail: Isabelle.Sioen@UGent.be

John Van Camp is a professor in food science and human nutrition. His address: Department of Food Safety and Food Quality, Ghent University, Coupure links 653, B-9000 Ghent, Belgium.

E-mail: John.Vancamp@UGent.be

Stefaan De Henauw is a professor in public health and nutrition epidemiology. His address: Department of Public Health, Ghent University, UZ-2 Blok A, De Pintelaan 185, B-9000 Ghent, Belgium.

E-mail: Stefaan.Dehenauw@UGent.be 